\title{
Aspectos clínicos, histopatológicos e moleculares da dermatosparaxia em ovinos White Dorper ${ }^{1}$
}

\author{
Danilo Giorgi A. Andrade ${ }^{2}$, Leonardo Fabrício Pavan², Rogério M. Amorim², Simone \\ B. Chiacchio ${ }^{2}$, Renée Laufer-Amorim ${ }^{2}$, Roberto C. Gonçalves ${ }^{2}$, Alexandre S. Borges ${ }^{2}$ \\ e José P. Oliveira-Filho ${ }^{2 *}$
}

\begin{abstract}
Andrade D.G.A., Pavan L.F., Amorim R.M., Chiacchio S.B., Laufer-Amorim R., Gonçalves R.C., Borges A.S. \& Oliveira-Filho J.P. 2014. [Clinical, histopathological and molecular aspects of the dermatosparaxis in White Dorper sheep.] Aspectos clínicos, histopatológicos e moleculares da dermatosparaxia em ovinos White Dorper. Pesquisa Veterinária Brasileira 34(5):443-448. Departamento de Clínica Veterinária, Faculdade de Medicina Veterinária e Zootecnia, Universidade Estadual Paulista, Campus de Botucatu, Distrito de Rubião Júnior s/n, Botucatu, SP 18618-000, Brazil. E-mail: zefilho@fmvz.unesp.br

Dermatosparaxis in animals is an autosomal recessive disorder of the connective-tissue clinically characterized by skin fragility and hiperextensibility. The disease in White Dorper sheep is caused by mutation (c. $421 \mathrm{G}>\mathrm{T}$ ) in the ADAM metalloproteinase with thrombospondin type 1 motif, 2 (ADAMTS2) gene. This study describes the dermatological, histological and the molecular findings of the dermatosparaxis in White Dorper sheep from a herd located in the center-west of São Paulo State. The herd consisted of one ram, four ewe and their lambs. In this herd two lambs had clinical signs consistent with dermatosparaxis. Histopathological evaluation of the affected skin of these two animals also revealed consistent findings with dermatosparaxis, characterized by dysplasia of the collagen, which were arranged in small and fragmented collagen bundles and with foci of degeneration of collagen. Prominent cutaneous appendages and severe hemorrhagic focus in dermis region associated with mild neutrophilic infiltrate in the deep dermis. PCR using DNA blood and specific primers to amplify the mutation region c. $421 \mathrm{G}>\mathrm{T}$ was optimized in order to perform molecular diagnosis of the disease. The direct sequencing of the PCR products proved that the two clinically affected animals had the mutation responsible for dermatosparaxis, previously described for this breed and allowed the definitive diagnosis of the disease. This is the first report of the dermatosparaxis in White Dorper sheep in Brazil and the methodology used to confirm the diagnosis could be used in future studies to assess the prevalence of this mutation in Brazil, allowing the adoption of measures to prevent the spread of this mutation in the Brazilian White Dorper herd.
\end{abstract}

INDEXS TERMS: Dermatopathias, dermatosparaxis, collagen, c.421G>T mutation, sheep.

RESUMO.- Dermatosparaxia em animais é uma doença autossômica recessiva do tecido conjuntivo caracterizada por fragilidade e hiperextensibilidade cutânea. A doença em ovinos White Dorper é provocada pela mutação c.421G >T no gene ADAM metalopeptidase com trombospondina tipo 1

\footnotetext{
${ }^{1}$ Recebido em 3 de maio de 2014.

Aceito para publicação em 22 de maio de 2014.

${ }^{2}$ Faculdade de Medicina Veterinária e Zootecnia, Universidade Estadual Paulista (Unesp), Departamento de Clínica Veterinária, Campus de Botucatu, Distrito de Rubião Júnior s/n, Botucatu, SP 18618-970, Brasil. *Autor para correspondência: zefilho@fmvz.unesp.br
}

motif, 2 (ADAMTS2). 0 objetivo deste estudo foi descrever os achados clínicos, moleculares e histopatológicos da dermatosparaxia em ovinos White Dorper de um rebanho localizado no Centro-Oeste Paulista. 0 rebanho era composto por nove animais, sendo um reprodutor, quatro matrizes e seus respectivos borregos. Dos nove animais examinados, dois apresentavam sinais clínicos compatíveis com dermatosparaxia. 0 exame histopatológico de amostras cutâneas das lesões destes dois animais revelou também achados compatíveis com dermatosparaxia, sendo caracterizados por epiderme e anexos cutâneos preservados e sem carac- 
terísticas atípicas; colágeno displásico arranjado em feixes pequenos, fragmentados e com focos de degeneração, anexos cutâneos proeminentes e na região da derme foco hemorrágico intenso associado a moderado infiltrado neutrofílico na derme profunda. Com o objetivo de realizar o diagnóstico molecular da enfermidade, uma PCR foi padronizada utilizando primers específicos desenhados para amplificar a região do gene ADAMTS2 que continha a mutação c. $421 G>T$ e o DNA obtido de amostras de sangue de todos os animais do rebanho. 0 sequenciamento direto dos produtos da PCR, comprovou que os dois animais clinicamente afetados possuíam a mutação responsável pela dermatosparaxia. A metodologia descrita neste estudo possibilitou o diagnóstico definitivo da doença. Segundo a literatura consultada, esta é a primeira vez que a dermatosparaxia é descrita em ovinos White Dorper no Brasil. A metodologia aqui descrita poderá ser empregada em estudos futuros que avaliem a prevalência desta mutação no Brasil, possibilitando a adoção de medidas que previnam a disseminação dessa mutação no rebanho brasileiro de ovinos White Dorper.

TERMOS DE INDEXAÇÃO: Dermatopatias, dermatosparaxia, colágeno, mutação c.421G>T, ovinos.

\section{INTRODUÇÃO}

Dermatosparaxia (astenia cutânea, cutis hiperelástica) em animais é uma doença autossômica recessiva do tecido conjuntivo caracterizada principalmente pela extrema fragilidade e hiperextensibilidade da pele (Scott 2007). Estas características cutâneas impedem que o animal seja mantido no sistema de criação, sendo descartado ou tirado de suas atividades habituais. Denominada em humanos como síndrome Ehler-Danlos tipo VIIC (Colige et al. 1999) a dermatosparaxia já foi descrita em gatos (Counts et al. 1980), cães (Panciello et al. 2003), cavalos (Badial et al. 2013), bovinos (Kawaguchi et al. 1988, Colige et al. 1999) e em algumas raças de ovinos (Fjolstad \& Helle 1974, Ramshaw et al. 1983, van Weeren-Keverling \& Koeman 1986, van Halderen \& Green 1988, Sucupira et al. 2009, Vaatstra et al. 2011, Zhou et al. 2012). A dermatosparaxia em ovinos da raça White Dorper já foi descrita na África do Sul (van Halderen \& Green 1988), Austrália (Aggs 2007), Espanha (Sucupira et al. 2009), Nova Zelândia (Vaatstra et al. 2011, Zhou et al. 2012) e Estados Unidos (Grant \& Patton 2012).

Assim como ocorre em humanos e em bovinos (Colige et al. 1999, Colige et al. 2004) a dermatosparaxia em ovinos White Dorper é ocasionada por uma mutação no gene ADAM metalopeptidase com trombospondina tipo 1 motif, 2 (ADAMTS2) (Zhou et al. 2012). Esta mutação (c.421G>T) quando em homozigose (presença de dois alelos mutantes, MM) é responsável pela formação de um códon finalizador prematuro, o qual produz a enzima ADAMTS2 inativa, levando ao processamento inadequado do pró-colágeno em colágeno (Zhou et al. 2012). Consequentemente, os animais com esta mutação apresentam os sinais clínicos de dermatosparaxia. Segundo a literatura consultada, casos de dermatosparaxia em ovinos White Dorper ainda não foram publicados no Brasil, sendo assim, o objetivo deste estudo foi descrever os achados clínicos, histopatológicos e moleculares da dermatosparaxia em ovinos White Dorper de um rebanho localizado no Centro-Oeste Paulista.

\section{MATERIAL E MÉTODOS}

Dados epidemiológicos do rebanho de ovinos White Dorper proveniente de uma propriedade localizada no município de Botucatu, Centro-Oeste Paulista, foram obtidos com o proprietário durante o atendimento clínico de um animal (borrego 6) com histórico e sinais clínicos compatíveis com a dermatosparaxia. Com o objetivo de realizar este estudo os nove ovinos que compunham o rebanho, incluído o borrego 6 e outro borrego que também apresentava sinais clínicos compatíveis com a dermatosparaxia (borrego 7), foram avaliados.

Esses animais foram submetidos ao exame físico (Feitosa 2008). 0 borrego 6 foi submetido à eutanásia e a necropsia in extremis. Amostras de pele dos dois ovinos com suspeita de dermatosparaxia e de um ovino controle (borrego 9) foram obtidas por biópsia, fixadas em formalina tamponada a $10 \%$, processadas de maneira habitual e incluídas em parafina. Cortes histológicos dos blocos de parafina com espessura de $5 \mu \mathrm{m}$ foram realizados e corados por hematoxilina e eosina (HE) e Tricrômio de Masson para posterior exame sob microscopia óptica de luz.

Com o objetivo de verificar a presença da mutação c. $421 \mathrm{G}>\mathrm{T}$ no gene ADAMTS2, responsável pela dermatosparaxia em ovinos White Dorper (Zhou et al. 2012), foram colhidas amostras de sangue dos nove ovinos. Em seguida o DNA genômico foi extraído das amostras sanguíneas com o Illustra GFX PCR DNA (GE ${ }^{\odot}$ Healthcare, Buckinghamshire, England), seguindo as recomendações do fabricante. Primers específicos que amplificam um fragmento de $231 \mathrm{pb}$, contendo a mutação c.421G>T, do gene ADAMTS2, foram desenhados utilizando o programa Primer Express ${ }^{\circledR}$ Software v3.0 (Life Technologies ${ }^{\mathrm{TM}}$, CA, USA), JP-ADAMTS2Forward 5'-GCCGCCTCTTCTACAATGTTAC-3' e JP-ADAMTS2 Reverse 5'-ACAAGGCCGTACTCACCA-3'. A PCR foi padronizada com volume final de 40 $\mu \mathrm{L}$, sendo $20 \mu \mathrm{L}$ de GoTaq $^{\circledR}$ Green PCR Master Mix (Promega ${ }^{\mathrm{TM}}$, WI, USA), $300 \mathrm{nM}$ de cada um dos primers, e 6,8 $\mu \mathrm{L}$ de água livre de nucleases. As condições de amplificação foram: denaturação inicial a $94^{\circ} \mathrm{C}$ por 5 minutos; seguida de 40 ciclos a $94^{\circ} \mathrm{C}$ por 30 segundos, $63^{\circ} \mathrm{C}$ por 1 minuto e $72^{\circ} \mathrm{C}$ por 1 minuto; e extensão final a $72^{\circ} \mathrm{C}$ por 7 minutos. Os produtos da PCR foram analisados em eletroforese em gel de agarose a $1,5 \%$ e os produtos com tamanho específico foram purificados usando o NucleoSpin ${ }^{\circledR}$ Gel and PCR Clean-up (Macherey-Nagel, Düren, Germany). Em seguida, 10 $\mu \mathrm{L}$ de produtos de PCR purificado com $5 \mu \mathrm{L}$ do primer JP-ADAMTs2Forw foram submetidos ao sequenciamento direto usando o BigDye ${ }^{\circledR}$ Terminator Cycle Sequencing Kit (Life Technologies ${ }^{\mathrm{TM}}$, CA, USA) e o sequenciador ABI 3500 Genetic Analyzer (Life Technologies $^{\mathrm{TM}}$, CA, USA). As sequências e os eletroferogramas obtidos foram analisados no programa Sequencher ${ }^{\mathrm{TM}} 5.1$ (Gene Codes, MI, USA) e comparados com a sequência normal do gene ADAMTS2 ovina (GenBank ${ }^{\mathrm{TM}}$ JF357978.1) utilizando o BLAST (Basic Local Alignment Search Tool, http://blast.ncbi.nlm.nih.gov/Blast.cgi).

\section{RESULTADOS}

Dados fornecidos pelo proprietário revelaram alto grau de consanguinidade entre os animais do rebanho, podendo ser comprovado pelo descontrole dos acasalamentos realizados na propriedade, uma vez que, as quatro matrizes do rebanho (matrizes 2 a 5) foram geradas de acasalamentos entre o reprodutor 1 , único reprodutor da propriedade, com quatro ovelhas já descartadas do rebanho, mas sem 
I

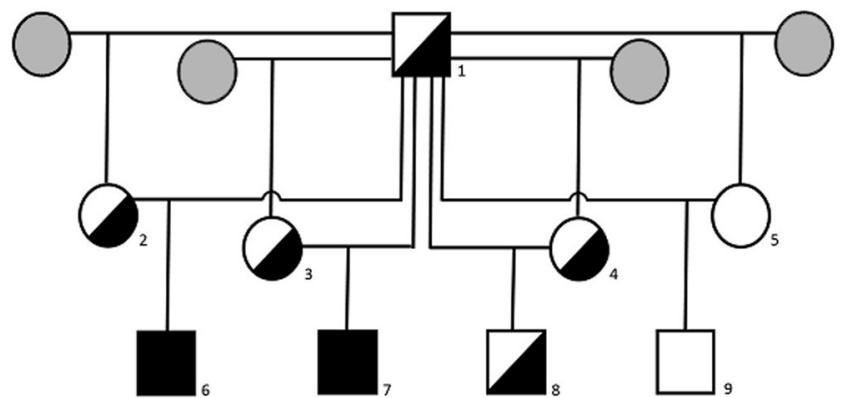

Fig.1. Heredograma do rebanho de ovinos da raça White Dorper, contendo as três gerações. Quadrado, macho; círculo, fêmea; figura hachurada, animais não avaliados; figuras preenchidas na cor preta, animais homozigotos para o alelo mutado (MM); figuras parcialmente preenchidas na cor preta, heterozigotos (NM) e figuras preenchidas na cor branca, animas sem a presença do alelo mutado (NN, wild type).

histórico de dermatopatia. Os borregos 6, 7, 8 e 9 eram provenientes dos acasalamentos entre o reprodutor 1 e estas matrizes, respectivamente. Ainda segundo o proprietário não havia relatos anteriores de nenhuma dermatopatia no rebanho (Fig.1). Ao exame físico, com exceção dos borregos 6 e 7 , os demais ovinos se apresentavam normais.
0 borrego 6 nasceu de parto normal e não apresentava nenhuma lesão cutânea ao nascimento, entretanto, ao exame clínico, ocorrido no segundo dia de vida, o animal apresentava dobras cutâneas, hiperextensibilidade da pele e feridas lacerantes bilaterais em região torácica. Além disso, estava inapetente e em decúbito, apresentava mucosa ocular pálida, desidratação de 8\%, hipoglicemia (58 $\mathrm{mg} / \mathrm{dL})$, hipotermia $\left(38^{\circ} \mathrm{C}\right)$, hipoproteinemia $(4,8 \mathrm{~g} /$ $\mathrm{dL}$ ), frequências cardíaca de 240 batimentos por minuto e m normais. respiratória de 60 movimentos por minuto, crepitação grossa à auscultação pulmonar e fimose. 0 animal não respondeu a terapia instituída com antimicrobianos, antinflamatórios e correção hidroeletrolítica, sendo submetido à eutanásia in extremis no dia seguinte. A necropsia revelou moderado hidrotórax; pulmão com acentuada broncopneumonia, áreas multifocais hemorrágicas nos lobos caudais e focos de enfisema nos lobos craniais e enterite mucopurulenta multifocal moderada. Além disso, foi evidenciado congestão hepática; rins com dilatação da pelve e cálices renais, estriações evidentes da cortical e focos hemorrágicos na medular e desprendimento difuso da pele.

0 borrego 7, assim como o borrego 6, havia nascido de parto normal e sem alterações cutâneas, mas no sexto dia

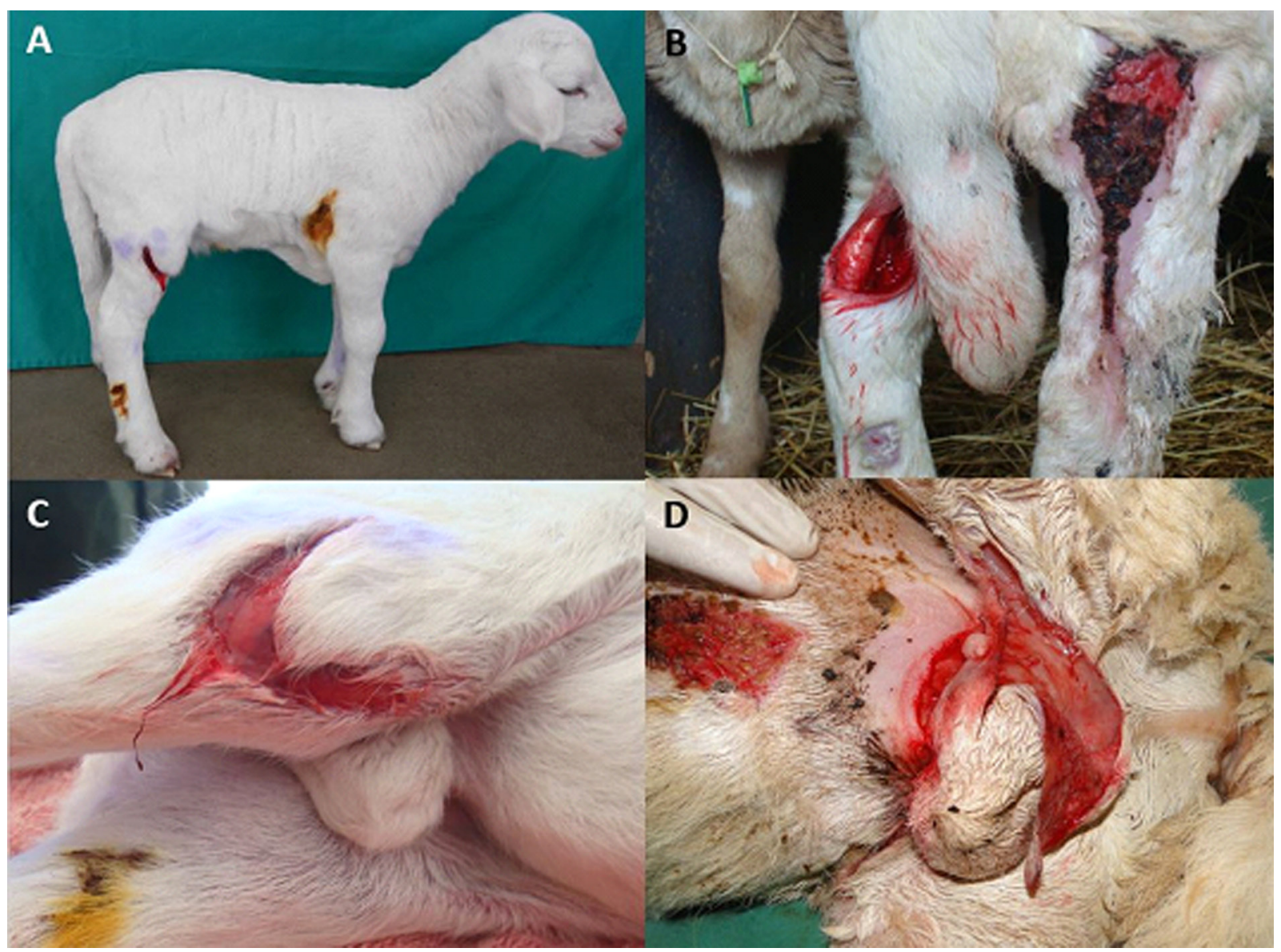

Fig.2. Lesões cutâneas do borrego 7 com dermatosparaxia. (A) Feridas lacerantes com presença de pele frouxa na região axilar e da articulação femorotibiopatelar direita. (B) Lesão lacerante na face posterior do membro pélvico esquerdo (MPE) e presença de extenso processo de reparação tecidual no MPD. (C) Lesão lacerante na região da articulação femorotibiopatelar direita. (D) Presença de processo de reparação tecidual na região ventral e lesão lacerante na região inguino-escrotal. 


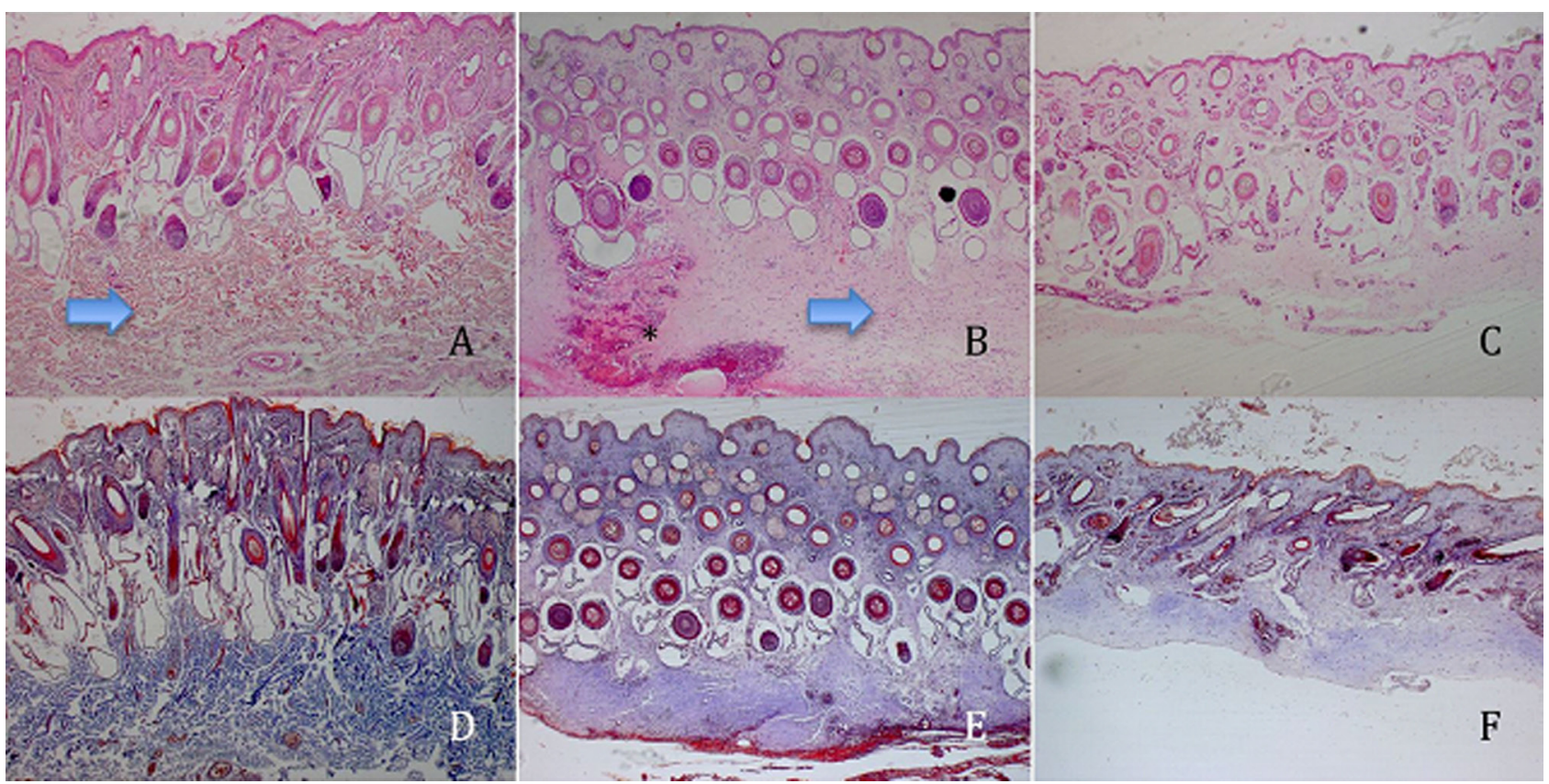

Fig.3. Secção histológica da pele de ovinos. (A,D) Pele normal com quantidade normal de colágeno (seta) (Borrego 9). (B,E), borrego 6. Redução da quantidade de colágeno (seta) e presença de hemorragia (*). (C,F) Redução da quantidade de colágeno (Borrego 7). (AC) HE, (D-F) Tricrômio de Masson, obj.5x.

de vida apresentou ferida na região da articulação femorotibiopatelar direita, sem sangramento profuso, porém com desprendimento da pele. Além disso, observou-se também a presença de seroma em região do peito e entrópio palpebral superior bilateral. Assim como no borrego 6, também não evidenciou-se alterações no sistema musculoesquelético. As demais funções avaliadas estavam dentro dos parâmetros de normalidade para a espécie. Durante o ano seguinte ao internamento, o animal 7 apresentou, com exceção da região da face, diversas feridas pelo corpo (Fig.2). Estes ferimentos ocorriam ao menor trauma, até mesmo durante sua contenção para realização dos curativos.

Os achados histopatológicos (Fig.3) das lesões cutâneas dos borregos 6 e 7 foram: epiderme e anexos cutâneos preservados e sem características atípicas; derme apresentando colágeno displásico arranjado em feixes pequenos, fragmentados e com focos de degeneração, e devido à hipoplasia do colágeno, os anexos cutâneos apresentavam-se mais proeminentes; na derme profunda destacava-se intenso foco hemorrágico, associado a moderado infiltrado neutrofílico.

Uma vez que os achados clínicos e histopatológicos dos borregos 6 e 7 eram compatíveis com dermatosparaxia, foi realizado o teste genético nestes dois animais, sendo que a mutação c.421G $>$ T no gene ADAMTS2, responsável pela dermatosparaxia em ovinos White Dorper (Zhou et al. 2012), foi evidenciada em homozigose (MM) nos borregos 6 e 7, confirmando o diagnóstico de dermatosparaxia. 0 teste molecular realizado nos demais animais do rebanho, os quais não apresentavam alterações clínicas, revelou que os animais 1 (reprodutor), 2 (mãe do borrego 6), 3 (mãe do borrego 7), 4 (mãe do borrego 8) e o borrego 8 eram heterozigotos (um alelo mutante e um alelo normal, $\mathrm{MN}$ ) para mutação. Enquanto que a matriz 5 (mãe do borrego
9) e o borrego 9 eram wild type, ou seja, não apresentavam nenhum dos alelos mutados (NN).

\section{DISCUSSÃO}

Humanos portadores da síndrome de Ehlers-Danlos tipo VIIC e bovinos com dermatosparaxia, apresentam uma redução na expressão do RNA mensageiro responsável pela síntese da proteína ADAMTS2 (Colige et al. 2004). Esta redução da expressão é ocasionada por mutações no gene ADAMTS2, sendo esta a causadora dos sinais de dermatosparaxia nestas espécies. A mutação responsável pela dermatosparaxia em ovinos, apenas foi identificada nos animais da raça White Dorper, que se assemelha àquela encontrada em humanos e bovinos, onde uma substituição de uma guanina por uma timina no nucleotídeo 421 da sequência codificante (c.421G $>\mathrm{T}$ ) provoca um códon finalizador prematuro (TAG) e consequentemente a produção de uma proteína ADAMTS2 truncada, contendo apenas o peptídeo sinalizador e parte do pró-domínio (Zhou et al. 2012). A produção desta proteína truncada afuncional leva a um defeito no processamento da porção N-terminal do pró-colágeno tipo I (Lapière et al. 1971). Uma vez que a conversão do pró-colágeno em colágeno é fundamental para garantir a adequada elasticidade e força tênsil da pele (Becker \& Timpl 1976), animais com esta mutação apresentam os sinais clínicos clássicos da dermatosparaxia, ou seja, pele hiperextensível e extremamente frágil, sendo facilmente rasgada ao menor trauma ou ao ser tracionada (Vaatstra et al. 2011).

Assim como nos borregos 6 e 7, a forma grave da dermatosparaxia também foi observada em cordeiros da raça White Dorper (van Halderen \& Green 1988, Sucupira et al. 2009, Vaatstra et al. 2011, Zhou et al. 2012) e da raça Norwegian (Fjolstad \& Helle 1974). Embora não provoque diretamente a morte do animal, a dermatosparaxia em sua 
forma grave é uma enfermidade considerada letal uma vez que as extensas feridas presentes ao nascimento ou poucas horas após se infeccionam facilmente podendo levar a um quadro de septicemia e morte dos cordeiros (Fjolstad \& Helle 1974). No presente estudo, um dos animais afetados apresentou quadro septicêmico decorrente das lesões de pele, e o outro animal apenas sobreviveu devido ao acompanhamento diário e ao tratamento das lesões de pele que frequentemente ocorreram nesses seis últimos meses. Apesar disso, o desenvolvimento ponderal desse animal foi semelhante ao borrego 9 , que não possuía nenhum alelo mutado, entretanto, as lesões cutâneas obrigatoriamente excluíram este animal de sistemas de produção comerciais.

Os achados clínicos, limitados a alterações cutâneas, observados nos borregos com dermatosparaxia do presente estudo se assemelham àqueles observados por outros autores em ovinos White Dorper (Van Halderen \& Green 1988, Sucupira et al. 2009, Vaatstra et al. 2011, Zhou et al. 2012). Embora o entrópio em ovinos aparentemente seja ocasionado pelo efeito aditivo de mutações recessivas em diferentes loci de genes (Basrur \& Yadav 1990), alterações no colágeno também podem provocar esse defeito. Uma vez que as causas genéticas envolvidas com o entrópio não foram investigadas no presente estudo, a presença do entrópio palpebral superior bilateral observada no borrego 7 , provavelmente seja decorrente da dermatosparaxia.

Nenhuma alteração diretamente relacionada à dermatosparaxia foi observada nos demais órgãos do borrego durante a necropsia, concordando com os achados observados em cordeiros White Dorper na Nova Zelândia (Vaatstra et al. 2011), contudo, os órgãos internos de cordeiros Norwegian com dermatosparaxia submetidos à necropsia, aparentemente eram mais friáveis que o normal e partes do trato digestivo ou artéria eram facilmente rompidas ao serem tracionadas com as mãos. Além disso, embora a cápsula articular também fosse friável, nenhuma alteração foi evidenciada nas articulações, ossos ou tendões destes animais (Fjolstad \& Helle 1974). Os achados histopatológicos das lesões cutâneas evidenciados nos animais do presente estudo são compatíveis com as descrições de outros autores em borregos White Dorper (van Halderen \& Green 1988, Sucupira et al. 2009, Vaatstra et al. 2011) e em outras raças de ovinos com dermatosparaxia grave (Fjolstad \& Helle 1974). Uma forma moderada da dermatosparaxia foi descrita na Austrália em ovinos adultos da raça Merino que desenvolveram lesões cutâneas durante a tosquia (Ramshaw et al. 1983). Esses animais apresentavam apenas 25\% da atividade da amino peptidase dos animais normais (Ramshaw 1984) e a avaliação histológica das lesões de pele destes animais revelou que as fibrilas de colágeno eram irregulares e agrupadas de forma desordenada nos feixes de fibras de colágeno. Estes feixes por sua vez não eram compactos e entrelaçados e com tendência a formar camadas em folhas na derme reticular como deveriam (Bavinton et al. 1985).

Doenças genéticas afetando ruminantes são relativamente comuns e podem ser economicamente importantes em determinadas raças, mas podem ser controladas com medidas efetivas e de baixo custo (Jolly 2002). 0 diagnóstico etiológico desse tipo de afecção, em muitas situações, não é realizado por negligencia ou completo desconhecimento da enfermidade pelo clínico ou por falta de metodologia diagnóstica. Assim como a dermatosparaxia, a maioria das enfermidades genéticas que afetam os ovinos também apresentam caráter hereditário autossômico recessivo (Basrur \& Yadav 1990). Uma vez que a enfermidade clínica só se manifesta em animais homozigotos (MM), a manutenção no rebanho de animais heterozigotos (MN) assintomáticos pode provocar o aparecimento de novos casos. Neste estudo, acasalamentos de um reprodutor heterozigoto com suas filhas heterozigotas geraram dois animais clinicamente afetados e outro animal heterozigoto, clinicamente sadio. Portanto, o reconhecimento clínico, bem como o diagnóstico etiológico da mutação responsável pela dermatosparaxia em ovinos, realizado sobretudo por testes moleculares, têm grande importância, uma vez que poderão ser adotadas medidas preventivas, visando a redução da ocorrência de novos casos e consequentemente, redução dos prejuízos financeiros.

Diversos países, como EUA, Nova Zelândia e Austrália, adotam testes comerciais, que identificam a mutação c. $421 \mathrm{G}>\mathrm{T}$ no gene ADAMTS2, como medida de controle para dermatosparaxia em ovinos da raça White Dorper. Em substituição aos testes comerciais ou à metodologia previamente descrita (Zhou et al. 2012), optou-se, no presente estudo, pela padronização de uma PCR utilizando primers especificamente desenhados para amplificar a região com a mutação e, em seguida, realizar o sequenciamento direto dos produtos da PCR. Como a metodologia descrita mostrou-se eficiente e segura e possibilitou o diagnóstico definitivo de dermatosparaxia, ela poderá ser empregada em teste de triagem pré-compra, no direcionamento dos acasalamentos ou em estudos que avaliem a prevalência dessa mutação no rebanho brasileiro de ovinos da raça White Dorper.

Agradecimentos.- Este trabalho foi financiado pela Coordenação de Aperfeiçoamento de Pessoal de Nível Superior (Capes) (Processo 23038. 007227/2012-04) e pela Pró-Reitoria de Pesquisa - PDI da Univ. Estadual Paulista (Processo 2328/002/14-PROPe/CDC).

\section{REFERÊNCIAS}

Aggs R. 2007. Screen test for fragile skin. Agriculture Today. Disponível em <http://www.dpi.nsw.gov.au/archive/agriculture-today-stories/ag-today-archives/august-2007/fragile-skin> Acessado em 03.mar. 2014.

Badial P.R., Rashmir-Raven A.M., Cagnini D.Q., Oliveira-Filho J.P., Cooley A.J., Cunha P.H.J., Kitchell B.E., Conceição L.G., Mochal C.A. \& Borges A.S. 2013. Marjolin's ulcer in two horses with hereditary equine regional dermal asthenia. J. Equine Vet. Sci. 33:515-522.

Basrur P.K. \& Yadav B.R. 1990. Genetic diseases of sheep and goats. Vet. Clin. North Am., Food Anim. Pract. 6:779-802.

Bavinton J.H., Peters D.E. \& Ramshaw J.A. 1985. A morphologic study of a mild form of ovine dermatosparaxis. J. Invest. Dermatol. 84:391-395.

Becker U. \& Timpl R. 1976. NH2-terminal extensions on skin collagen from sheep with a genetic defect in conversion of procollagen into collagen. Biochemistry 15:2853-2862.

Colige A., Nuytinck L., Hausser I., Van Essen A.J., Thiry M., Herens C., Adès L.C., Malfait F., Paepe A.D., Franck P., Wolff G., Oosterwijk J.C., Smitt J.H., Lapière C.M. \& Nusgens B.V. 2004. Novel types of mutation responsible for the dermatosparactic type of Ehlers-Danlos syndrome (Type VIIC) and common polymorphisms in the ADAMTS2 gene. J. Invest. Dermatol. 123:656-663.

Colige A., Sieron A.L., Li S.W., Schwarze U., Petty E., Wertelecki W., Wilcox 
W., Krakow D., Cohn D.H., Reardon W., Byers P.H., Lapière C.M., Prockop D.J. \& Nusgens B.V. 1999. Human Ehlers-Danlos syndrome type VII C and bovine dermatosparaxis are caused by mutations in the procollagen I N-proteinase gene. Am. J. Hum. Genet. 65:308-317.

Counts D.F., Byers P.H., Holbrook K.A. \& Hegreberg G.A. 1980. Dermatosparaxis in a Himalayan cat: I. Biochemical studies of dermal collagen. J. Invest. Dermatol. 74:96-99.

Feitosa F.L.F. 2008. Semiologia Veterinária: a arte do diagnóstico. $2^{\mathrm{a}}$ ed. Roca, São Paulo. 754p.

Fjolstad M. \& Helle O. 1974. A hereditary dysplasia of collagen tissues in sheep. J. Pathol. 112:183-188.

Grant D. \& Patton W. 2012. Dermatosparaxis in White Dorpers. Disponível em <http://www.dorper.org/PDF_SALE/DERMATOSPARAXIS.pdf> Acessado em 3 mar. 2014.

Jolly R.D. 2002. Screening for genetic diseases in cattle. Aust. Vet. J. 80:284285.

Kawaguchi T., Fukazawa H., Naito Y. \& Okada K. 1988. Dermal dysplasia characterized by collagen disorder-related skin fragility in a cow. Am. J. Vet. Res. 49:965-971.

Lapière C.M., Lenaers A. \& Kohn L.D. 1971. Procollagen peptidase: an enzyme excising the coordination peptides of procollagen. Proc. Natl Acad. Sci. USA 68:3054-3058.
Paciello O., Lamagna F., Lamagna B. \& Papparella S. 2003. Ehlers-DanlosLike Syndrome in 2 Dogs: Clinical, Histologic, and Ultrastructural Findings. Vet. Clin. Pathol. 32:13-18.

Ramshaw J.A., Peters D.E., Jones L.N., Badman R.T. \& Brodsky B.B. 1983. Ovine dermatosparaxis. Aust. Vet. J. 60:149-151.

Ramshaw J.A. 1984. A mild form of ovine dermatosparaxis. Coll. Relat. Res. 4:441-451.

Scott D.W. 2007. Color Atlas of Farm Animal Dermatology. Blackwell Publishing Professional, Ames. 252p.

Sucupira M.C.A., Arcaute M.R., Lacasta D., Perez M.J., Ramos J.J., Verde M.T. \& Ferrer L.M. 2009. Enfermedades Congénitas y Hereditarias de la Piel de los Cordeiros. I. Albéitar, Espanha, p.36-37.

Vaatstra B.L., Halliday W.D. \& Waropastrakul S. 2011. Dermatosparaxis in two white Dorper lambs. N. Z. Vet. J. 59:258-260.

Van Halderen A. \& Green J.R. 1988. Dermatosparaxis in White Dorper sheep. J. S. Afr. Vet. Assoc. 59:45.

Van Weeren-Keverling B.A. \& Koeman J.P. 1986. A form of dermatosparaxis in a Texel lamb. Tijdschr. Diergeneeskd. 111:173-177.

Zhou H., Hickford J.G. \& Fang Q. 2012. A premature stop codon in the ADAMTS2 gene is likely to be responsible for dermatosparaxis in Dorper sheep. Anim. Genet. 43:471-473. 